\title{
Los petroglifos de Pool Balam, Yucatán
}

\author{
Alfredo Barrera Rubio
}

Resumen: Las labores de rescate arqueológico en una carretera del nororiente de Yucatán permitieron el hallazgo de una cueva denominada Pool Balam en maya yucateco. En una de las cámaras se encontraron una serie de petroglifos esculpidos en una estalagmita. El análisis de estos motivos nos indica una vinculación de estas representaciones con la cosmovisión maya, particularmente con el agua y el jaguar en su advocación del sol en su recorrido nocturno y como guardián, protector, ser sobrenatural del monte $y$ de las cuevas. De acuerdo a los datos cerámicos, existen evidencias de ocupación desde el Preclásico Tardío hasta el Posclásico.

Palabras clave: cueva, petroglifo, cara, agua, jaguar, guardián, protector.

Enviado a dictamen: 17 de marzo de 2009

Aprobación: 2l de mayo de 2009

Revisiones: 1

Alfredo Barrera Rubio, licenciado en ciencias antropológicas en la especialidad de arqueología, por la Facultad de Antropología de la Universidad Autónoma de Yucatán. Investigador del Centro INAH Yucatán, Mérida, Yucatán; México. Temas de especialización: cultura maya prehispánica, patrón de asentamiento, pintura mural, iconografía y cosmovisión. Correo electrónico: abarrerar@prodigy.net.mx.
Abstract: The archaeological rescue on a northeastern road of the state of Yucatán, led to the finding of a cave named Pool Balam, in the maya yucatecan language. In one of the chambers we found a series of petroglyphs carved in a stalagmite. The analysis of these motifs indicated a link between these representations and the maya cosmovision, particularly with the water and the jaguar in its personification of the sun on its nocturnal journey and as the guardian, protector, and supernatural being of the forest and the caves. According to the ceramic's data, there exists evidence of occupation that dates from the Late Pre-classic to the Post-classic.

Key words: cave, petroglyph, faces, water, jaguar, watchman, protector.

\section{Introducción}

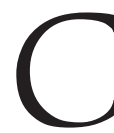
omo consecuencia de las labores de protección del patrimonio cultural que el Centro que escribe ha tenido la responsabilidad de atender las tareas de peritajes, rescates y salvamentos arqueológicos en la región nororiental de dicha entidad. El área mencionada comprende fundamentalmente el municipio de Tizimín y los municipios aledaños de Río Lagartos, San Felipe, Panabá, Sucilá, Espita, Calotmul, Dzilam Bravo, Dzilam González y Buctzotz (Figura 1). 
En dicha zona predomina actualmente la actividad ganadera y como resultado hay un cambio drástico en el paisaje natural ya que la vegetación originaria de selva mediana subcaducifolia se ha transformado en extensas zonas de praderas cultivadas de pastizales. En esta región también son comunes los cenotes y las rejolladas ${ }^{1}$ o depresiones naturales del terreno que conforman nichos ecológicos para cultivos. Nichos muy importantes durante la época prehispánica y que requieren de mucha humedad.

En esta región no existe zona arqueológica abierta al público y, por ende, tampoco hay custodios del INAH. Mientras se desarrolló y estuvo vigente la investigación en dicha zona, con más frecuencia hubo presencia de arqueólogos en la región. Sin embargo, en la actualidad, debido a la falta de apoyo por parte de las autoridades para continuar la investigación en el área, la presencia del INAH se limita a la atención de peritajes, rescates y salvamentos arqueológicos.

El patrimonio arqueológico existente en el nororiente de Yucatán es relevante y extenso y está sujeto a afectaciones constantes por obras de infraestructura: carreteras, uso de maquinaria agrícola para la preparación de terrenos, para la siembra de pastizales, para la actividad ganadera, traslado y acarreo de piedras de estructuras arqueológicas por volqueteros y saqueo.

Por otra parte, en las ciudades grandes del oriente, como Tizimín, es común encontrar vestigios prehispánicos conurbados detectados durante la construcción de calles o la preparación de terrenos para la construcción de viviendas y fraccionamientos.

A lo anterior habría que agregar la nula presencia de personal de vigilancia del INAH en tan amplia región. La investigación, conservación y difusión del patrimonio cultural se limitan a las actividades de rutina realizadas por los pocos arqueólogos que tenemos presencia en la zona.

En los últimos años, las labores de rescate y salvamento arqueológico realizados en el oriente de Yucatán nos han permitido obtener una muestra importante del asentamiento rural prehispánico. Esta muestra nos ha dado indicios de las características de la sociedad maya en su desarrollo en esta región. Nuestras evidencias indican que en estas épocas tempranas existió un poblamiento importante en el área, es decir, durante el Preclásico Medio y Tardío este poblamiento no tuvo continuidad, mientras que en otros momentos tuvo un mayor desarrollo hacia períodos posteriores.

Es necesario destacar que toda la información generada a raíz de los rescates y salvamentos es de gran importancia para poder conocer el desarrollo cultural de los mayas, planificar la investigación científica y la conservación del patrimonio cultural en la región.

\section{Prospección y rescate arqueológico de la carretera E. C ${ }^{2}$. Buctzotz-Sucilá-San Francisco, municipio de Buctzotz}

En atención a una solicitud del titular de la Comisión ${ }^{3}$ de Vías Terrestres del estado de Yucatán, durante los días comprendidos del 4 al 22 de abril del año 2005, se llevaron a cabo labores de prospección arqueológica en el tramo 0+000 al km.9+680 de la carretera E.C.(BuctzotzSucilá)-San Francisco, municipio de Buctzotz (Figura 2), en virtud de la construcción de la carretera hacia dicho poblado (Domínguez y Estrada s/f).

Durante estas labores se registraron un total de 47 plataformas prehispánicas y 92 estructuras de tipo chiich $^{4}$ (Domínguez y Estrada s/f: 63, 64), las cuales fueron ubicadas de acuerdo al kilometraje y distancia del eje del trazo de la nueva carretera. Los días comprendidos del 2 al 27 de mayo del 2005 se llevaron a cabo las tareas de rescate arqueológico de las estructuras prehispánicas. 41 plataformas y 87 chiich fueron afectadas por la construcción de la carretera mencionada (Díaz s/f).

Como resultado de las excavaciones, se analizaron 3,928 tiestos, de los cuales se pudieron identificar 3,849, lo que equivale a $97.98 \%$ de la muestra total (Pérez s/f: 41). La mayoría de la cerámica fue de uso doméstico, lo cual está acorde con las características de las estruc- 
turas excavadas. El período de mayor ocupación fue el Preclásico Tardío y hubo una leve ocupación durante el Preclásico Medio, Clásico Temprano y Clásico Tardío (Pérez, s/f: 40, 41).

Como consecuencia de las labores de prospección arqueológica, se hizo un importante hallazgo en el km. 3+660 del trazo de la carretera mencionada: se encontró una rejollada con una cueva con petroglifos y fuentes de agua (Domínguez y Estrada) (Figura 3).

Esta cueva con petroglifos es conocida por lo campesinos mayas de la región como Pool Balam que significa en maya yucateco "cabeza de jaguar". La cueva se reportó por primera vez y forma parte de una rejollada y de un contexto habitacional prehispánico que se exploró como parte del rescate arqueológico mencionado. En el interior de la cueva se hallaron elementos culturales de relevancia: petroglifos y material cerámico cuyo análisis e interpretación nos permite adentrarnos en la cosmovisión de los antiguos mayas (Figura 4).

En virtud de que dichos vestigios arqueológicos se encuentran en el costado poniente de la carretera que estaba en construcción, y debido a que la cueva se desarrolla hacia el oriente, por debajo de la carretera, solicitamos que ésta se desviara hacia el oriente.

Como no pudo moverse el trazo de la carretera, propusimos como alternativa que se verificara la resistencia de las bóvedas de piedra caliza de la caverna para adoptar medidas técnicas en la construcción de este tramo, y evitar tanto el desplome de las mismas ante el aforo y peso vehicular, como el daño a los vestigios arqueológicos.

También recomendamos que se evitara la vegetación asociada y que el drenaje pluvial de la carretera se canalizara hacia el costado oriente para evitar la contaminación de las fuentes de agua de la caverna.

\section{Antecedentes arqueológicos e históricos}

En la región donde se llevó a efecto la prospección y rescate arqueológico no hay registro de sitio arqueoló- gico alguno en el Atlas arqueológico de Yucatán (Garza Tarazona y Kurjack, 1980) ni en los registros posteriores de sitios en esta zona (Velázquez Morlet et al. 1988).

Esta área está ubicada dentro de la provincia prehispánica de Ah Kin Chel (Roys, 1957) del siglo XVI (Figura 5). De acuerdo con Sergio Quezada, Dzizantún fue el centro político donde residía un poder central del cuchcabal de dicha región, siendo el fundador Ah Chel, yerno de un sacerdote de Mayapán (Quezada, 1993: 162).

En cuanto a las características de las estructuras residenciales que registramos en el trazo de la carretera, las de mayores dimensiones se localizaron en las cercanías de la comisaría de San Francisco.

En las inmediaciones de dicho poblado hacia el suroeste, como a 500m. del cabo del pueblo, en un área que se pretendía usar como banco de material para la carretera, se encontró un pequeño núcleo de estructuras prehispánicas (Figura 6). Este consiste en varias plataformas residenciales y un pequeño montículo parcialmente afectado con maquinaria, cuando se explotó dicha zona para banco de material. Este asentamiento prehispánico no había sido reportado con anterioridad por lo que lo registramos con $\mathrm{GPS}^{5}$.

Hacia el suroeste encontramos evidencias de plataformas habitacionales con metates asociados ${ }^{6}$. También se encontró cerca del cabo del pueblo, al sur, una aguada con un ojo de agua ${ }^{7}$.

\section{La cueva de Pool Balam}

Como hemos señalado, en el km. 3+660, al oeste del trazo de la carretera mencionada, se encontró la cueva de "Pool Balam". ${ }^{8}$ Su ubicación fue tomada con GPS, siendo sus coordenadas geográficas N.21ำ 12.273' y W $88^{\circ} 27.281^{\prime}$.

La cueva se desarrolla a partir de una rejollada o ko'op cuyos costados oeste y sur presentan una depresión en la que aflora la piedra caliza o karst, mientras que en los costados oriente y norte se desarrolla una fractura de la misma, que da lugar a un mayor hun- 
dimiento del terreno y a la formación, en este sector, de una cueva y de un abrigo rocoso. En el interior de la misma existen varios afloramientos acuíferos que provienen del manto freático.

Para un mejor registro se llevó a cabo el levantamiento topográfico de la rejollada y la cueva (Figura 7). En el interior de la rejollada aún predomina la vegetación de selva mediana subcaducifolia. Entre las plantas que pudimos observar están la ceiba (Ceiba pentandrata), el álamo (Ficus cotinifolia), pich (Enterolobium cyclocarpun), ramón (Brosimum alicastrum), pixoy (Guazuma ulmifolia), roble (Ehretia tinifolia), ${ }^{9}$ Huaya (Talisia olivaeformis), plátanos y palmas.

De acuerdo a un campesino maya, el tipo de tierra que predomina en este espacio es el "chich luum", es decir, tierra con piedras. Esta característica facilita la absorción del agua. Las rejolladas constituyeron nichos ecológicos de gran importancia para la agricultura prehispánica ya que permitieron cultivos de plantas altamente preciadas por los mayas, como el cacao.

En el interior de este espacio se pudieron registrar tres estructuras arqueológicas (Figura 7): una plataforma de poca elevación (E.1); una pequeña construcción rectangular hecha de piedra suelta (E. 2) de cuya esquina sureste se desprende una albarrada; $y$, en el costado norte de esta estructura, otra construcción de forma absidal (E.3), resto de una choza maya, posiblemente post-hispánica.

En las inmediaciones de la rejollada pudimos localizar hacia el sur, como parte de las actividades de rescate arqueológico, una estructura habitacional cuadrangular (E.18) de pequeñas dimensiones $(4.10 \mathrm{~m}$. de ancho por $5.25 \mathrm{~m}$. de largo y $20 \mathrm{~cm}$. de altura) y al norte de la rejollada tres estructuras de tipo "chich" (E.31, E.32 y E.33) (Díaz, s/f: 42-48). Al excavarse un pozo en la primera estructura, se encontraron dos entierros, uno primario y el otro secundario. El primero se encontró en una cista, con ofrenda de dos platos (uno en el cráneo y el otro en las extremidades inferiores), un vaso fragmentado (a nivel del tórax) y una mano de moler (incompleta) a la altura de los huesos de las manos y un pendiente de hueso que consiste en un colmillo de animal (Díaz, s/f: 42-44) (Figura 8).

Hacia el costado sureste de la rejollada, en una bajada abrupta del terreno, se accede al interior de esta cueva e inmediatamente se puede observar, hacia el poniente, una estalagmita de grandes dimensiones que presenta, hacia el oriente, un perfil ondulado o de cascada. Es ahí donde se puede observar, en diferentes niveles, una serie de petroglifos, representaciones de rostros o caras. Algunos de estos petroglifos llevan debajo barras verticales (Figura 9).

\section{Descripción de la cueva}

Como hemos señalado, la cueva se desarrolla en forma de abrigo rocoso y con dos cámaras principales ubicadas al oriente y al norte de la rejollada a las cuales hemos denominado como cámaras uno y dos, respectivamente (Figura 10). Entre ambas cámaras existe la entrada a una pequeña cavidad que da acceso a un pasadizo muy estrecho.

Cámara l.- La cámara uno o de los petroglifos, como hemos indicado, se desarrolla en el costado oriente de la rejollada. Su acceso se da a partir de la carretera, por una vereda que desemboca en el costado sureste de la mencionada cámara. Lo primero que destaca en su interior es una enorme estalagmita con petroglifos esculpidos principalmente en su cara oriente.

$\mathrm{Al}$ sureste y al pie de este elemento se encuentra una piedra con "pocitas" característica de sitios con agua y donde se celebraban rituales relacionados con este elemento (Figura 11). Por ejemplo, los santuarios del culto a Tlaloc, en los cerros de la cuenca de México, están asociados a afloramientos vistosos de rocas naturales tallados con relieves, petroglifos "maquetas" y "pocitas", los cuales constituyen misteriosos vestigios arqueológicos que no han sido interpretados en el contexto adecuado (Broda, 2003: 60). 
En el costado oriente se pueden observar dos afloramientos de agua: uno de pequeñas dimensiones ubicado en la parte central y oriente de la cámara; y otro, de mayores dimensiones, situado hacia el norte de la misma. En varios partes de esta cámara se pueden observar gran cantidad de piedras producto del derrumbe de algunos sectores de la bóveda de karst. Hacia el costado sureste de esta cámara se desarrolla un pasadizo estrecho en el que pudimos encontrar algunos tiestos de cerámica en la superficie.

Cámara 2.- La cámara dos se desarrolla en el costado norte de la rejollada. Es una cámara de menores dimensiones que la anterior y en su interior se localizaron dos pequeños afloramientos de agua. A diferencia de la cámara anterior, en esta no observamos la presencia de petroglifos.

\section{Cronología}

Durante los recorridos por las cámaras y pasadizos de la cueva se pudo recolectar material cerámico de superficie (17 tiestos) (véase Tabla 1), cuyo análisis ${ }^{10}$ nos arrojó evidencias de ocupación desde el Preclásico Tardío hasta el período colonial. Del Preclásico Tardío (100 a.C.-300 d.C.) contamos con la presencia del grupo Saban, tipo Chancenote estriado: variedad Chiquilá. Del Clásico Temprano/Terminal (300-600 d.C.) encontramos cerámica del Grupo Timucuy, tipo Timucuy naranja policromo: variedad Timucuy. En el Clásico Tardío/Terminal (600-900 d.C./1100 d.C.) consideramos que hay un traslape parcial y encontramos tiestos del Grupo Muna tipos Muna pizarra: variedad Engobe cafetoso, Sacalum negro sobre pizarra: variedad Engobe cafetoso, Akil impreso: variedad engobe cafetoso, y Yokat estriado: variedad Yokat; del Grupo Dzitas tipo Dzitas pizarrra: variedad Dzitas, tipo Chacmay inciso: variedad Chacmay; y del Grupo Kukulá crema: variedad Kukulá. Del Posclásico (1100-1550) hallamos cerámica del Grupo Mama tipo Mama rojo: variedad mama. También se encontró un fragmento de Olivera vidriada de la época colonial.
Si tomamos en cuenta la cronología de las estructuras aledañas excavadas, así como la totalidad de las que se exploraron en las cercanías del trazo de la carretera, la ocupación mas intensa en esta región se da durante el Preclásico Tardío y disminuyó en los períodos posteriores (Pérez, s/f). Por ello es altamente probable que los petroglifos de Pool Balam correspondan a esta datación y que, en consecuencia, la población maya de aquella época utilizara la caverna para actividades rituales.

\section{Los petroglifos de la cámara 1}

Los petroglifos de la cámara 1 se hallan esculpidos en una estalagmita que tiene una forma similar a un cono con dimensiones de $4.20 \mathrm{~m}$. de altura y $2.80 \mathrm{~m}$. en su base. Ésta se desplanta sobre una superficie de roca 3.60 m. de largo (Figura 12).

La estalagmita presenta, desde la parte más elevada hacia abajo, un perfil escalonado hacia el oriente. En cada nivel se encuentran agrupaciones de petroglifos. Éstos se disponen principalmente en la cara oriental de la citada estalagmita, en dirección a uno de los afloramientos de agua.

Los motivos que los mayas representaron en esta estalagmita son 19 caritas (18 al oriente 1 al norte), barras o bandas (dos agrupaciones de tres, debajo de dos caras ubicadas al oriente), trazos circulares (uno al sureste), polígonos (dos al sureste y uno al norte) y "pocitas" (seis al oriente).

Las caras.- Los motivos principales consisten de una serie de caras o rostros representados de una manera esquematizada, algunas veces acompañados de barras dispuestas verticalmente. Las caras son representadas por contornos circulares o rectangulares que simbolizan la cabeza, aunque hay casos en el que se carece de este diseño o sólo se hizo un trazo parcial. También tenemos un ejemplar en el que el rostro esta enmarcado con un trazo lineal cóncavo, con puntas en sus extremos.

En el interior del contorno que forma la cabeza, dos círculos y a veces semicírculos o diseños almen- 
drados representan los ojos; y otro círculo o un trazo semicircular o lineal, la boca. En algunos casos ésta no se representa. En sólo uno de los ellos se esculpieron a ambos lados de la boca, en el área de los pómulos, dos círculos.

Las barras o bandas.- Tres barras verticales, que a primera vista parecen representar el numeral 5 cada una en el sistema aritmético maya, se desarrollan en la parte inferior de cada una de las dos caras principales, ubicadas en la parte superior de la estalagmita. No obstante, por el contexto me inclino a pensar que podrían representar más bien bandas que simbolizan el flujo del agua a partir de las caras.

Los polígonos y elementos curvilíneos.- Estos motivos son generalmente un contorno circular, rectangular o trapezoidal sin ningún diseño en su interior. Es menos frecuente que las caras antes descritas.

"Las pocitas".- Son perforaciones circulares relacionadas con el agua, ya que al llover se acumula el líquido en estos agujeros y se establece un vínculo simbólico entre ambos elementos.

Distribución.- Hemos agrupado los petroglifos tomando en cuenta su cercanía y el nivel en el que se encuentran ubicados, de arriba hacia abajo. Sabemos que entre los cánones del arte maya, los niveles superiores eran jerárquicamente más importantes que los inferiores, por lo que si aplicamos este criterio a los petroglifos que analizamos, los más importantes se encuentran representados en la parte superior de la estalagmita.

Primer nivel.- El primer agrupamiento se ubica en la parte superior o primer nivel de la estalagmita y consiste en cuatro "pocitas" o perforaciones dispuestas alrededor del contorno de la parte superior de la estalagmita, debajo de las cuales se encuentran otras dos (Figura 13).

Segundo nivel.- Debajo, en un segundo nivel, hay una cara sin contorno, es decir, solo con ojos y boca. Hacia el lado izquierdo de este motivo se encuentran evidencias de vandalismo ya que se arrancaron capas carbonatos de calcio, que posiblemente tuvieron algún diseño grabado (Figura 14).

Tercer nivel.- Consiste en tres petroglifos de cara que miran hacia el oriente, en orden descendente, de los cuales dos tienen tres bandas o barras verticales y el primero de ellos es el que lleva dos círculos en el área de los pómulos (Figura 15). En este mismo nivel, en el costado norte de la estalagmita, alejado del agrupamiento anterior, se encuentra otro petroglifo de cara con contorno rectangular (Figura 16).

Cuarto Nivel.- En él se encuentra un agrupamiento de cinco caras, de las cuales una tiene el enmarcado en forma de trazo lineal-curvilíneo-cóncavo (Figura 17). En este mismo nivel, pero en la parte sur-oriente, se ubican dos trazos: uno en círculo y el otro rectangular. En el costado norte de este mismo nivel se encuentra un diseño poligonal (Figura 18).

Quinto nivel.- Este es el penúltimo nivel donde se ubica una agrupación de cuatro caras: dos con contorno y dos sin contorno, así como tres elementos circulares. Un poco más al sur y hacia arriba, se ubica un polígono trapezoidal (Figura 19).

Sexto nivel.-En el último nivel se hallan dos caras, de las cuales una tiene un contorno rectangular (Figura 20).

\section{Reportes previos de petroglifos de caras}

Las caras son representaciones muy comunes y frecuentes en las cuevas de otras partes del estado de Yucatán, particularmente en las que se ubican en la región del Puuc. También son comunes en otros estados vecinos, e incluso en algunos tan alejados como San Luís Potosí o Sinaloa. También los encontramos en otros países americanos y centroamericanos como República Dominicana, Cuba, Nicaragua, Costa Rica, Panamá y en Sudamérica en Venezuela, Perú, Chile y Argentina (Casado López, et al. 1988: 94; Küne, 2008a, 2008b).

En las cuevas de La Patana y Cabo Cruz en Cuba existen representaciones de caras asociadas a estalag- 
mitas, donde se ha aprovechado este elemento natural como sugerente o complemento para hacer la figura (Casado López, et al. 1988: 94).

En Nicaragua tenemos ejemplos de petrograbados de caras en las islas del Lago Nicaragua, particularmente, Ometepe y en las costas del Pacífico (Baker, 2008: 205). En Costa Rica también es un motivo figurativo común (Künne, 2008a: 225-226) y en Panamá también tenemos reportes de este motivo en el sitio Nancito (Chiriquí) (Künne, 2008b: 256, fig. 100).

En el caso del área maya Mattias Strecker (1985: 20, nota 1) hace una síntesis de varios casos en los que las caras son esculpidas en estalagmitas y estalactitas, en cuevas y cenotes.

En Chiapas tenemos referencias de este tipo de representaciones en los petroglifos de las rocas $18 \mathrm{y}$ 16 de la Finca Las Palmas (Weber y Strecker, 1980: 40; Strecker, 2008: 61,62, figs. 6 y 7). Otros investigadores, además de hacer referencia a los petroglifos de caras de la Finca Las Palmas, reportan las del sitio MP-6 y de la región de Peñitas (Navarrete, et al. 1993: $82-84$ figuras 48, 49, 50, 51, 52, 53, 54 y 55).

En Quintana Roo, "las caras" han sido reportadas en cuevas como Aktunkoot, Cueva del danzante, Cueva de las Caritas (Martos López, 2002: figs. 105, 106, 107 y 108), Cenote Tancah (Miller, 1975: 11, 1977: 112-114; 1982: 87-89; Rissolo, 2008: 98), Ich tun, Tres reyes, Actun Xooch, Actun Toh, Xca'ca'ch'en (al otro lado de la frontera con Yucatán) y Pak Ch'en (Rissolo, 2008: 98, 100-103).

En Belice, estas caras se encuentran en Petroglyph Cave (MacNatt, 1996: fig.5), Te Tun Cave (Bonor y Martinez, 1995: 256-257), Pottery Cave (Bonor, 2002), Actun Uayazba Kab (Helmke y Awe, 1998, 2001), Jaguar Paw Cave (Helmke, Awe y Grifith, 2008: 119), Actun Halal (Griffith y Helmke, 2000; Griffith y Morehart, 2001), Actun Chapat (Griffith et al. 2003) y Actun Chuplal (Dema et al., 2002).

En Guatemala, Teobert Maler reporta en el siglo XIX una estalactita con una cara grabada en una cueva cercana al Río Usumacinta (1903, T.II: 202). En tiempos recientes, Michel Siffre (1979) documenta en la región del Petén caras esquemáticas representadas de frente en las cuevas de Pusilhá, Jovelte y Jutéria. Al norte y oeste de Poptun se encuentran la cueva de Corosal con representaciones de caras (Siffre, 1979: 163-165, figuras 94-100) y la cueva que Siffre llama Poxte y que fue posteriormente llamada Balam Nah I (Stone, 2008: 139) tiene representaciones de caras sencillas, bordeadas de círculos (Brady, et al. 2001).

En una cueva del Río Candelaria en el norte de Alta Verapaz se reporta un petroglifo de cara (Carot, 1989: 26-28, figs. 19 y 47 ).

Las representaciones de caras también se tallaron sobre cantos rodados como es el caso del denominado Manantial, que esta en el piedmont Pacífico del departamento de Quetzaltenango, entre Flores Costa Cuca y Génova (Stone y Ericastilla, 1999: 778-779), donde se halló en la parte superior tres caras grabadas (Stone, 2008: 144).

En el departamento de Jutiapa, en cinco localidades de las montañas, entre Asunción Mita y la ciudad de Jutiapa se describen grabados rupestres, de los cuales uno de ellos es una cara simple de frente (Mata, 1973).

En Honduras también se reportan representaciones de petrograbados de caras (MacKrittck, 2008: 177) en los sitios de Picila, Departamento de Intibuca; en el este de Honduras en los sitios de Oropolí y Morocelí, Departamento de El Paraiso (MacKrittck, 2008: 184, 188, 189).

En Yucatán, los primeros registros de estos motivos fueron del explorador y cónsul de los E.U.A. Edward H. Thompson, quien llevó a cabo dos expediciones a la cueva de Loltún: La primera en 1888-89 y la segunda en 1890-91 (Thompson, 1897). Conjuntamente con sus colaboradores realizó excavaciones en ambas cueva, tomó fotografías y registró algunos petroglifos de "caras", aunque no hizo una referencia explicita a estos diseños (Thompson, 1897, lámina III, Fig.l y fig. 8: 16).."

Teobert Maler, a fines del siglo XIX (1890-1) realizó registros de petroglifos de caras en la cueva de Loltún en el sur del Estado de Yucatán y en el oriente, en la 
cueva Cixhuh, cerca de Valladolid (Strecker, 1981:27, figs. 2, 3, 6, 7 y 10).

Por otra parte, Henry Mercer en 1896 publicó su obra "The Hill-Caves of Yucatán", en la cual incluye reportes de estos motivos que encontró en cuevas de la serranía del puuc, como Actún Ceh, exploradas por él en 1895 (Mercer, 1975 Figura 10).

Reportes más recientes de este tipo de motivos los encontramos en las cuevas de Mis y Petroglifos (Strecker, 1984: 22,23 y 24, figs. 2, 3, 5, 8, 10, 11, 12 y 14), Ehbis, ${ }^{12}$ Xcosmil $^{13}$ y Cahum (Strecker, 1985: 16, 17, 18 y 19, figs. 1, $3,6,8,9,10,14,15,16,18,19$, 20; véase también Strecker y Stone, 2008), todas ellas ubicadas en el municipio de Oxkutzcab.

\section{Análisis e Interpretación de los motivos}

Respecto al significado de las representaciones de caras debemos señalar que la mayoría de los reportes sobre petrograbados en forma de caras se limita a su descripción y en muchos casos se carece de una ubicación espacial, es por eso que no existen los elementos para una discusión amplia del simbolismo de estos motivos.

Algunos investigadores los han interpretado según su asociación temporal, como encarnación de seres o fuerzas suprasensibles a las cuales se identifica como divinidades. En el caso de Yucatán, se asocian al culto de divinidades que habitan en las cuevas, como el alux (Casado López, et al. 1988: 94). También se sugiere que estas caras representan deidades que recibieron ofrendas de sacrificio (Strecker, 1985: 21).

Mi propuesta interpretativa, en este caso, es que el significado de estos motivos deberá de asociarse con el pensamiento cosmogónico de los mayas en relación al agua y a la concepción de la cueva como entrada al inframundo.

Nosotros entendemos la cosmovisión como "... la visión estructurada en la cual los antiguos mesoamericanos combinan de manera coherente sus nociones sobre el medio ambiente en que vivían, y sobre el cosmos en que situaban la vida del hombre" (Broda, 1991: 462).

En este mismo sentido la cosmovisión plantea explorar las múltiples dimensiones de cómo se percibe culturalmente la naturaleza (Broda, 2004: 21). El término alude a una parte del ámbito religioso y se liga a las creencias, a las explicaciones del mundo y al lugar del hombre en relación con el universo.

El ritual establece el vínculo entre los conceptos abstractos de la cosmovisión y los actores humanos. Al ser una parte substancial de la religión, implica una activa participación social (Broda, 2004: 21). En este sentido los petroglifos de la cueva de Pool Balam son vestigios materiales de una actividad ritual de los pobladores prehispánicos y es a través de la interpretación de su simbolismo cosmogónico por medio de la arqueología, de las fuentes etnohistóricas y etnográficas que podemos aproximarnos a la cosmovisión de los pobladores del área.

Los ritos prehispánicos pertenecían a un elaborado calendario de fiestas basado en la observación del año solar, las estaciones y los ciclos agrícolas. Por eso, es sobre todo en el culto campesino vinculado con los ciclos agrícolas, las estaciones y el paisaje que rodea las aldeas donde se han preservado importantes elementos de la cosmovisión prehispánica en el contexto del sincretismo con la religión católica (Broda, 2001).

De esta manera, la ubicación de la mayoría de los petroglifos hacia el oriente y la perspectiva del observador, desde el interior, hacia el poniente, permiten ver la puesta de sol y por ende el descenso del astro rey al inframundo. Recordemos que en la cosmovisión mesoamericana el sol se transforma en un jaguar en su recorrido nocturno por el inframundo (Figura 21).

El jaguar simbolizaba la noche y el poder nocturno, era el nahual por excelencia, sobre todo de los chamanes y los hombres de poder, como los reyes y los sacerdotes (González, 2001: 123).

El nombre maya de la cueva también puede servirnos como hilo conductor para ir vinculando el pensamiento 
maya en este contexto. Hemos señalado que Pool Balam significa cabeza de jaguar. Balam puede interpretarse en la cosmovisión maya como "guardián, protector, ser sobrenatural (Diccionario Cordemex, 1980: 32).

El jaguar guarda un estrecho vinculo con las deidades asociadas al inframundo y a las diversas puertas de entrada a este sector del universo, como son las cuevas y el interior de los montes (Valverde Valdés, 2005: 75).

Thompson identifica, como uno de los elementos de lo que él llama "grupo del inframundo", tres puntos negros en forma de triángulo que simbolizarían las manchas del felino, identificadas por él como una deidad y que portan todos los seres vinculados de alguna forma con esta parte del mundo maya (Thompson, 1975: 280).

En cuanto a la representación glífica del jaguar, a éste se le asocia con el décimo cuarto día del calendario: Ix, término maya que se ha interpretado como jaguar y pluma y cuyas variantes son piel, corteza, hechizo. Estas variantes están relacionadas entre sí ya que el jaguar es un disfraz del hechicero; y la piel, la corteza y la pluma que envuelven, cubren y ocultan como disfraz (Barrera Vásquez, 1941: 83) (Figura 22).

Thompson coincide con la interpretación anterior ya que para él Ix es el Balam y éste corresponde al ocelotl del tonalpohualli. Tiene un glifo muy estilizado pero el elemento constante son tres manchas negras que se podrían identificar con las del jaguar (Thompson, 1975: 82). Es probable que gran parte de las representaciones de caras en los petroglifos de Pool Balam hagan alusión, en este sentido, al jaguar.

Por otra parte, los petroglifos de caras también guardan cierta similitud con el glifo del día ahau, que es el símbolo que significa dignatario, gran señor o sol (Thompson, 1975: 87, 89), y no olvidemos la estrecha relación del jaguar con el astro rey (Figura 23).

Al balam se le atribuye, además de ser señor del campo, el hecho de pasearse por el aíre desde donde prorrumpeen prolongados silbidos que lo hacen más respetabley temible. Por ello, muchas veces le llaman yum balam, esto es, padre y señor (Carrillo, 1846 IV. 103-6).
Los campesinos mayas le dan mucha importancia a los aires ya que según su dirección pueden ser benéficos o causar enfermedades. Esto es muy importante cuando se accede a una cueva ya que éstas tienen protector o guardián. En este sentido el aprovechamiento del nicho ecológico que representa la rejollada, así como el agua de la cueva, requirió del permiso de las deidades protectoras de estos elementos para lo cual el campesino, los chamanes o sacerdotes debieron de llevar a cabo ritos y ceremonias propiciatorias de los protectores del campo y de la cueva.

\section{Conclusiones}

Pool Balam nos ejemplifica cómo los mayas pobladores de la región nororiental del estado compartieron creencias similares a las de los mayas de otras regiones de la península y de la zona maya. La rejollada como nicho ecológico era un bien preciado por los mayas ya que, por sus características ambientales, permitió el cultivo de plantas como el cacao que alto valor tenía en la época prehispánica. El aprovechamiento de este recurso, así como de los mantos acuíferos, requirió del permiso de las divinidades protectoras del monte y de las cuevas. Según mi interpretación, una de esas deidades fue principalmente el jaguar como guardián, ser protector, sin descartar que otras pudieran también tener un papel aún no identificado.

La ubicación y la orientación de la estalagmita, con los petroglifos esculpidos principalmente en su cara oriente y la posición del observador hacia el poniente, permitieron a los mayas prehispánicos observar el ocaso solar y, en su cosmovisión, la transformación de éste en jaguar.

Por otra parte la estalagmita de los petroglifos bien pudo funcionar como un marcador calendárico solar ya que se pueden apreciar las puestas de sol en los días más significativos del año, como los solsticios y los equinoccios. Investigaciones futuras nos permitirán confirmar esta aseveración. 


\section{Notas}

${ }^{1}$ Según la Enciclopedia Yucatán en el Tiempo, las rejolladas son "También llamadas jollas o rejollas, derivadas de hoyo u hondonadas. En maya se les conoce con los términos ko'op y kom, que significan: depresión o hundimiento del terreno. Son depresiones circulares con un diámetro casi nunca superior a los $30 \mathrm{~m}$., un declive que se pronuncia de la periferia al centro, resultado del desplome de la bóveda de un cenote millones de años atrás, cuyo fondo se va rellenando con sedimentos arcillosos y tierra arrastrada por las lluvias, por lo que no almacena agua. Son áreas muy fértiles, tanto por la tierra de aluvión como por la proximidad de la capa freática para sembrar aguacate, mango, mamey, nance, anona, saramuyo, guanábana, entre otros cultivos. Son frecuentes en la porción centro-oriental del estado, específicamente en el área comprendida entre las localidades de Yaxcabá, Tunkas, Cenotillo, Calotmul, Tinum y Pisté"

(Tomo V: 302).

${ }^{2}$ Entronque Carretero.

${ }^{3}$ Actualmente Dirección de Vías Terrestres del Gobierno del Estado de Yucatán.

${ }^{4}$ Chich es un término del maya yucateco con el que se denomina a la piedra suelta de pequeño tamaño. En la arqueología yucateca se aplica a las concentraciones circulares de reducidas dimensiones, hechas por los mayas.

${ }^{5}$ Marca Garmín, modelo map7. Sus coordenadas geográficas son №21 14.446 y W 88ㅇ29.146.

${ }^{6}$ Este agrupamiento lo ubicamos también con GPS siendo las coordenadas N 21ำ14.40`4 y W 80ํ⒉164'.

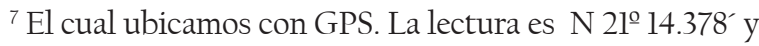
W 88을. $28.935^{\prime}$.

${ }^{8}$ El propietario del terreno donde se ubica esta cueva es el señor Florencio Salinas Osorio.

${ }^{9}$ Los nombres científicos de las plantas las tomamos de la obra Nomenclatura, forma de vida, uso, manejo y distribución de las especies vegetales de la Península de Yucatán Etnoflora Yucatanense Fascículo 20 de Alberto Are- llano, et al. 2003. Universidad Autónoma de Yucatán. Facultad de Medicina Veterinaria y Zootecnia.

${ }^{10}$ El análisis del material cerámico estuvo a cargo del pasante de arqueología Wilbert Cruz Alvarado, y para la ubicación cronológica tuvimos la asesoría del arqlgo. Carlos Peraza Lope.

${ }^{11}$ Debemos señalar que aunque Thompson fue el primer explorador de Loltún, su informe no se publica hasta 1897, un año después (1896) que diera a la luz pública Henry Mercer su obra de "Hill Caves of Yucatán", donde refiere sus exploraciones de las cuevas yucatecas de la región Puuc, entre ellas Loltún que visitó en 1895.

${ }^{12}$ En esta cueva las caras fueron esculpidas sobre una estalagmita.

${ }^{13}$ Aquí el autor reporta seis caras dibujadas en pintura negra, además de otras esculpidas en piedra (véase figura 6). También reporta un petroglifo de cara con los dos círculos en los pómulos (véase figura 18), de manera similar a una de las caras principales de Pool Balam.

\section{Bibliografía}

Arellano Rodríguez et al. (2003), "Nomenclatura, forma de vida, uso, manejo y distribución de las especies vegetales de la Península de Yucatán" en Etnoflora Yucatanense, Fascículo 20, Mérida Yucatán: Universidad Autónoma de Yucatán, Facultad de Medicina Veterinaria y Zootecnia.

Baker, Suzanne, 2008, "Arte Rupestre de Nicaragua”, en Martin Kuenne y Matthias Strecker (eds.) Arte Rupestre de México Oriental y América Central, Bolivia: SIARB, www.siarb-bolivia.org/esp/principal.htm. Versión electrònica de (2003), Arte Rupestre de México Oriental y América Central, suplemento no. 16 de la revista Indiana, Berlin: Instituto Iberoamericano, Fundación Patrimonio Cultural Prusiano y el Gbr. Mann Verlag, pp.197-218.

Barrera Vásquez, Alfredo (1941), "Sobre la significación de algunos nombres de signos del calendario maya", 
en Los mayas antiguos, México: El Colegio de México, Fondo de Cultura Económica.

Bonor Villarejo, Juan Luís (2002), Caves Branch, Distrito de El Cayo, Belice. Reporte arqueológico de campo a la Foundation for the Advancement of Mesoámerican Studies (FAMSI). URL: http/www.famsi.org/ reports/96044/index.html.

Bonor Villarejo, Juan Luís y Carolina Martínez Klemm (1995), "Trabajos recientes en la región de Caves Branco", Distrito de el Cayo Belize, en Los Investigadores de la Cultura Maya, núm 4, Campeche: Universidad Autónoma de Campeche, pp. 250-267.

Brady, James y Gene Ware (2001),"Las inscripciones de Naj Tunich: Avances recientes de imagen multi-espectral", en Juan Pedro Laporte, Ana Claudia Monzón de Suasnávar y Bárbara Arroyo(eds.) XIV Simposio de Investigaciones Arqueológicas en Guatemala, Vol. 2, Guatemala, Ministerio de Cultura y Deportes, pp. 10171025.

Broda, Johanna (1991), "Cosmovisión y observación de la naturaleza: el ejemplo del culto a los cerros de Mesoámerica”, en Johanna Broda, Stanislaw Iwaniszaewski, Lucrecia Maupomé (eds.) Arqueoastronomía y etnoastronomía en Mesoámerica, no.4, México: Instituto de Investigaciones Históricas, UNAM. Serie Historia de la

Ciencia y la Tecnología, pp. 461-500.

Broda, Johanna (2001), "La etnografía de la fiesta de la Santa Cruz: una perspectiva histórica”, en Johanna Broda y Felix Baéz-Jorge (eds.) Cosmovisión, ritual e identidad de los pueblos indígenas de México, México: Fondo de Cultura Económica-Conaculta, pp. 165-238.

Broda, Johanna (2003), "El culto mexica de los cerros de la cuenca de México: apuntes para la discusión sobre graniceros", en Graniceros. Cosmovisión y meteorología indígenas de Mesoámerica, México: El Colegio Mexiquense, Universidad Autónoma de México, pp. 49-90.

Broda, Johanna (2004), "Introducción", Historia y vida ceremonial en Johanna Broda y Catherine Good Eshelman (coords.) Las comunidades mesoamericanas: Los ritos agrícolas, México: Instituto Nacional de Antropo- logía e Historia, Universidad Autónoma de México, pp. 15-32.

Carot, Patricia (1989), "Arqueología de las cuevas del norte de Alta Verapaz", en Cuadernos de estudios guatemaltecos, Núm. 1, México: Centre d’ Études Mexicaines et Centroaméricaines.

Carrillo, Fray Estanislao (1846), "Papeles sueltos del padre Carrillo. Fantasmas”, en: Registro Yucateco, Tomo IV „, Mérida: Imprenta de Castillo y Compañía, pp. 103-106.

Casado López, Maria del Pilar et al. (1988), “Subproyecto de pictografías y petrograbados”, en Adriana, Velásquez Morlet, Edmundo López de la Rosa, Maria del Pilar Casado López y Margarita Gaxiola (eds.) Zonas arqueológicas Yucatán, México: INAH, pp. 91-98.

Enciclopedia Yucatán en el tiempo. Raúl E. Casares G. Cantón et al. Director, (1999), Enciclopedia Alfabética Tomo V, Mérida: Inversiones Cares.

Dema, Brian et al. (2002), "Preliminary investigations in Actun Chuplal,Macal Valley,Belize", en Jaime J. Awe y Carolyn M. Audet (eds.): The Belize Valley Archaeological Reconnaissance Project: A report of the 2001 field season. Departament of Anthropology Occasional Paper 6, Durham: University of New Hampshire, pp. 68-75.

Díaz Cruz, José Luis (2005), Rescate arqueológico ampliación carretero San Francisco, Informe de actividades, Mérida: Centro INAH Yucatán.

Diccionario Maya Cordemex (1980), Mérida: Ediciones Cordemex.

Domínguez Aguilar, Luís Daniel y Silvia Victoria Estrada Vielma (2005), Recorrido Buctzotz-Tizimín-San Francisco, Informe Técnico, Mérida: Centro INAH Yucatán.

Griffith, Cameron S. y Christophe G. Helmke (2000), "Preliminary investigations in Actun Halal,Macal Valley, Cayo Belize" en Jaime J. Awe y David F. Lee (eds.): The Western Belize Regional Cave Project: A report of the 1999 field seaso,. Departament of Anthropology Occasional Paper 3, Durham: University of New Hampshire.

Griffith, Cameron S. y Christoper T. Morehart (2001), "A Preliminary report on the excavations and con- 
tinued investigations of Actun Halal Belize", en Jaime J. Awe y David F. Lee (eds.) The Western Belize Regional Cave Project: A report of the 2000 field seaso, Durham: Departament of Anthropology Occasional Paper 4. University of New Hampshire.

Garza Tarazona, Silvia y Eduard B. Kurjack (1980), Atlas arqueológico del Estado de Yucatán, 2 vols., México: SEPINAH.

Griffith, Cameron S., Reiko Ishihara y Sarah Jack (2003), " Report on the $3^{\text {rd }}$ and $4^{\text {th }}$ seasons of archaeological investigations in Actun Chapat", en Jaime J. Awe (ed.) The Western Belize Regional Cave Project: A report of the 2002 field season, Departament of Anthropology Occasional Paper 6, Durham:, University of New Hampshire.

González Torres, Yolota (2001), "El Jaguar”, en Yolotl González Torres (coord.) Animales y plantas en la cosmovisión mesoamericana, México: CONACULTA-INAH Plaza y Valdés Editores. pp. 123-144.

Helmke, G.B. Cristophe, Jaime J. Awe (1998), "Preliminary analysis of the pictographs, petroglyphs, and sculptures of Actun Uayazba Kab ,Cayo Distrit, Belize", en Jaime J. Awe (ed.) The Western Belize Regional Cave Project: A report of the 1977 field season. Occasional Paperl, Durham: University of New Hampshire, pp. 141-199.

Helmke, G.B. Cristophe y Jaime J. Awe (2001), “Interpretations of the Pictographs and Petroglyphs of Actun Uayazba Belize: Implications for Ancient Maya Cave Rituals". Ponencia en 66th Meeting of the Society for American Archaeology (SAA), New Orleans, Lousianna.

Helmke, G.B. Cristophe y Jaime J. Awe y Cameron S. Griffith (2008), "Arte rupestre de Belice", en Martin Kuenne y Matthias Strecker (eds.) Arte Rupestre de México Oriental y América Central, Bolivia: SIARB, www.siarb-bolivia.org/esp/principal.htm. Versión electrònica de (2003), Martin Kuenne y Matthias Strecker (eds.) Arte Rupestre de México Oriental y América Central, suplemento no. 16 de la revista Indiana, Berlin: Instituto Iberoamericano, Fundación Patrimonio Cultural Prusiano y el Gbr. Mann Verlag, pp. 111-132.

Künne,Martín, 2008a "El Arte Rupestre de Costa Rica", en Martin Kuenne y Matthias Strecker (eds.) Arte Rupestre de México Oriental y América Central, Bolivia: SIARB, www.siarb-bolivia.org/esp/principal.htm. Versión electrònica de (2003), Arte Rupestre de México Oriental y América Central, suplemento no. 16 de la revista Indiana, Berlin: Instituto Iberoamericano, Fundación Patrimonio Cultural Prusiano y el Gbr. Mann Verlag, pp. 217-240.

Kúnne,Martín,2008b, "El arte rupestre de Panamá", en Martin Kuenne y Matthias Strecker (eds.) Arte Rupestre de México Oriental y América Central, Bolivia: SIARB, www.siarb-bolivia.org/esp/principal.htm. Versión electrònica de (2003), Arte Rupestre de México Oriental y América Central, suplemento no. 16 de la revista Indiana, Berlin: Instituto Iberoamericano, Fundación Patrimonio Cultural Prusiano y el Gbr. Mann Verlag, pp. 241-258.

MacNatt, Logan. 1996, “Cave Archaeology of Belice”, en Journal of Cave and Karst Studies, 58 (2): 81-99, Hunstville, Alabama.

Maler, Teobert (1903), Researches in the Central Portion of the Usumacinta Valley.. Vol. II, No.2, S.77-216, Massachusetts: University, Cambridge.

Martos López, Luis Alberto (2002), Por las tierras mayas del oriente: Arqueología en el área de Calica, México: INAH.

Calica, Mata Amado, Guillermo (1973), "En Jutiapa”, en La Hora, 26 de mayo, Guatemala.

Mckittrik, Alison, 2008, "Arte Rupestre en Honduras", en Martin Kuenne y Matthias Strecker (eds.) Arte Rupestre de México Oriental y América Central, Bolivia: SIARB, www.siarb-bolivia.org/esp/principal.htm. Versión electrònica de (2003), Arte Rupestre de México Oriental y América Central, suplemento no. 16 de la revista Indiana, Berlin: Instituto Iberoamericano, Fundación Patrimonio Cultural Prusiano y el Gbr. Mann Verlag, pp.177-196. 
Mercer, Henry C., 1975 The Hill-Caves of Yucatán. Reprint. Norman: University of Oklahoma Press.

Miller, Arthur G., 1975, "Archaeological Investigations at Tulúm and Tancah, Quintana Roo, México: A progress report of the 1974 season", en Contributions of the University of California Archaeological Research Facility, Studies in Ancient Mesoamerica, vol.27, núm. 2, Berkeley, California, pp. 10-16.

Miller, Arthur, 1977, "The Maya and the sea: Trade and Cult at Tancah and Tulúm, Quintana Roo, México", en Benson, Elizabeth (ed.) The Sea in the Precolumbian World. A conference at Dumbarton Oaks, October $26^{\text {th }}$ and $27^{\text {th }}$ 1974, Washington: Dumbarton Oaks Research Library and Collection, pp. 96-140.

Miller, Arthur (1982), On the edge of the sea. Mural Painting at Tancah-Tulum, Quintana Roo, México Washington: Dumbarton Oaks Research Library and Collection.

Navarrete, Carlos et al. (1993), Un catálogo defrontera, México: UNAM

Peréz Amezquita, Wendy Lorena (2005), Informe Preliminar del Análisis del Material Cerámico del Salvamento San Francisco, Yucatán: Centro INAH Yucatán.

Quesada, Sergio (1993), Pueblos y caciques yucatecos 1550 1580, México: El Colegio de México, Grupo Edición.

Rissolo, Dominique, 2008,"El arte rupestre de Quintana Roo", en Martin Kuenne y Matthias Strecker (eds.) Arte Rupestre de México Oriental y América Central, Bolivia: SIARB, www.siarb-bolivia.org/esp/principal.htm. Versión electrònica de (2003), Arte Rupestre de México Oriental y América Central, suplemento no. 16 de la revista Indiana, Berlin: Instituto Iberoamericano, Fundación Patrimonio Cultural Prusiano y el Gbr. Mann Verlag, pp. 93-110.

Roys, Ralph (1957), The Political Geography of the Yucatán Maya, Washington: Carnegie Institution of Washington.

Siffre, Michel (1979), Mysteriuses civilizations dans les entailles de la terre. A la recherche de l'art des cavernes du pays maya, Nice : Editions Alain Leveuvre.
Stone, Andrea (2008),"Arte rupestre de Guatemala", en Martin Kuenne y Matthias Strecker (eds.) Arte Rupestre de México Oriental y América Central, Bolivia: SIARB, www.siarb-bolivia.org/esp/principal.htm. Versión electrònica de (2003), Arte Rupestre de México Oriental y América Central, suplemento no. 16 de la revista Indiana, Berlin: Instituto Iberoamericano, Fundación Patrimonio Cultural Prusiano y el Gbr. Mann Verlag, pp.133-156.

Stone, Andrea y Sergio Eric Castilla Godoy (1999), "Registro de arte rupestre en las Tierras Altas de Guatemala: resultados del reconocimiento de 1997", en XII Simposio de Investigaciones Arqueológicas en Guatemala, Guatemala: Instituto de Antropología e Historia, pp. 775-790.

Strecker, Matthias (1981), "Exploraciones arqueológicas de Teobert Maler en cuevas yucatecas", en Boletín de la Escuela de Ciencias Antropológicas de la Universidad de Yucatán, Vols. 8 y 9, Nos. 49 y 49, Mérida: Talleres Gráficos y Editorial Zamna, pp. 20-31.

Strecker, Matthias (1984), "Cuevas mayas en el municipio de Oxkutzcab, Yucatán (1): cuevas Mis y Petroglifos", en Boletín de la Escuela de Ciencias Antropológicas de la Universidad de Yucatán, Vol.12, No. 68:21-28, Mérida; Impresiones Profesionales.

Strecker, Matthias (1985), "Cuevas mayas en el municipio de Oxkutzcab, Yucatán (II): cuevas Veis, Xcosmil y Cahum", en Boletín de la Escuela de Ciencias Antropológicas de la Universidad de Yucatán, Vol.12, Núm.70, Mérida: Impresiones Profesionales, pp. 16-23.

Strecker, Matthias, 2008, "Arte rupestre de Tabasco y Chiapas”, en Martin Kuenne y Matthias Strecker (eds.) Arte Rupestre de México Oriental y América Central, Bolivia: SIARB, www.siarb-bolivia.org/esp/ principal.htm. Versión electrònica de (2003), Arte Rupestre de México Oriental y América Central, suplemento no. 16 de la revista Indiana, Berlin: Instituto Iberoamericano, Fundación Patrimonio Cultural Prusiano y el Gbr. Mann Verlag, pp. 43-64. 
Strecker, Matthias y Andrea Stone. 2008, "Arte rupestre de Yucatán y Campeche”, en Martin Kuenne y Matthias Strecker (eds.) Arte Rupestre de México Oriental y América Central, Bolivia: SIARB, www. siarb-bolivia.org/esp/principal.htm. Versión electrònica de (2003), Arte Rupestre de México Oriental y América Central, suplemento no. 16 de la revista Indiana, Berlin: Instituto Iberoamericano, Fundación Patrimonio Cultural Prusiano y el Gbr. Mann Verlag, pp.67-91.

Thompson, Edward H. (1897), Cave of Loltun, Yucatán. Report of the Explorations by the Museum,1888-89 and
1890-91 Memoirs of the Peabody Museum of American Archaeology and Ethnology, Vol.1, no. 2, Cambridge: Harvard University.

Thompson, J. Eric (1975), Maya Hieroglyphic Writing, Norman: University of Oklahoma Press.

Valverde Valdés, Maria del Carmen (2004), Balam, México: UNAM.

Velázquez Morlet, Adriana et al. (1988), Zonas arqueológicas Yucatán, México: INAH.

Weber, Gertrud y Matthias Strecker (1980), Die Petroglyphen der Finca Las Palmas (Chiapas, México, Akademische Duck-und Verlagsanstalt, Graz. 


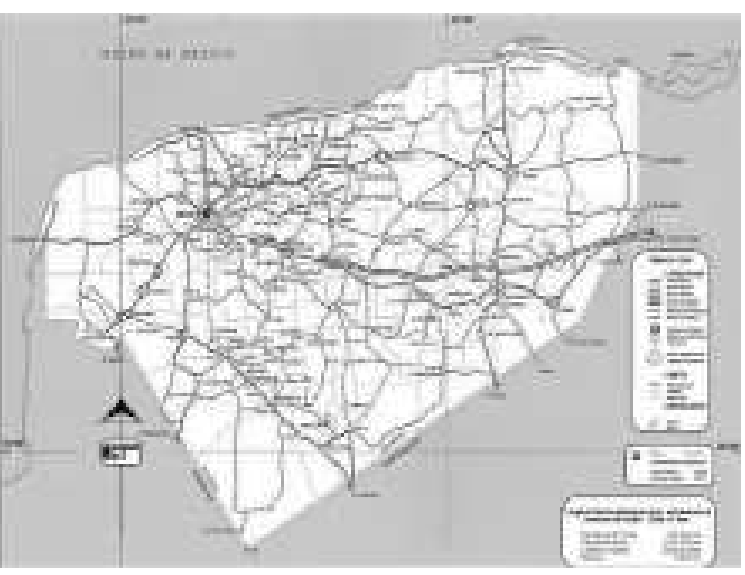

Figura No. 1

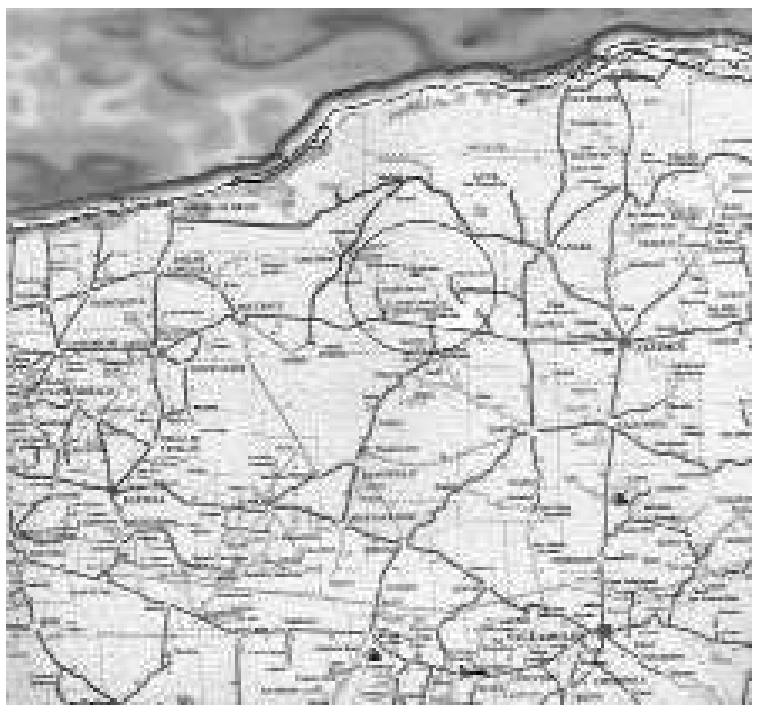

Figura No. 2

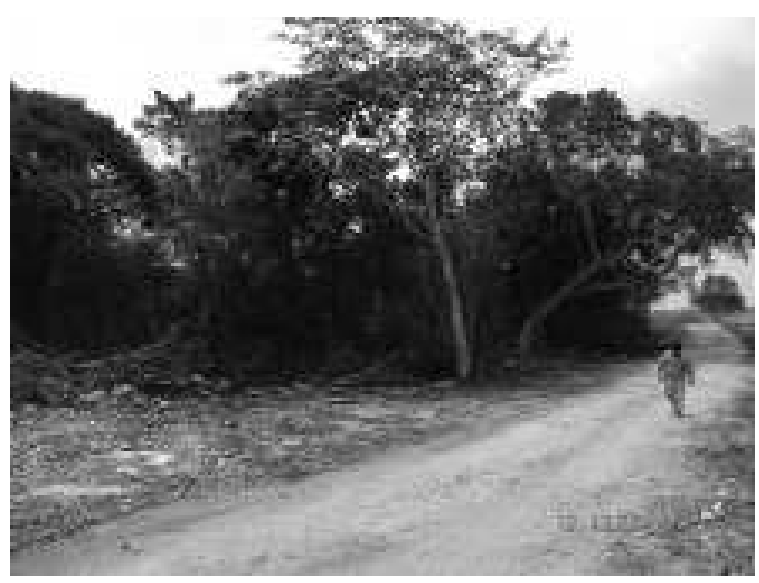

Figura No. 3

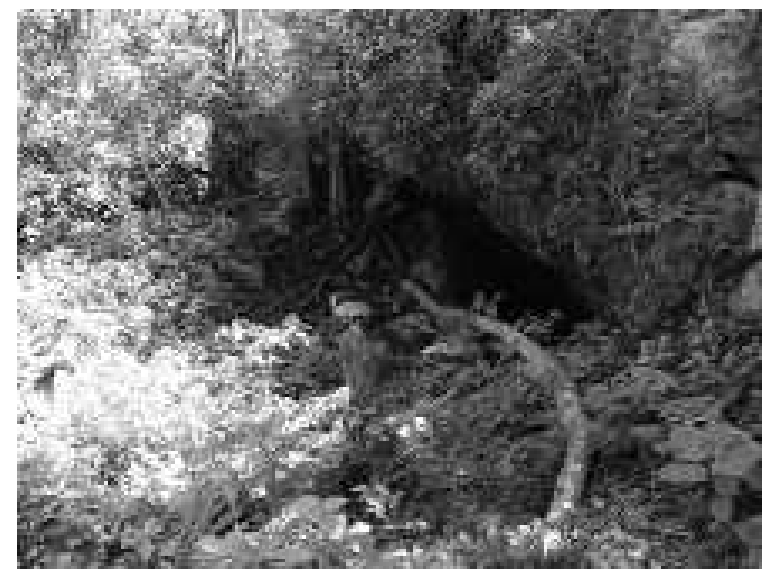

Figura No. 4 
Los Petroglifos de Pool BaLAm, Yucatán

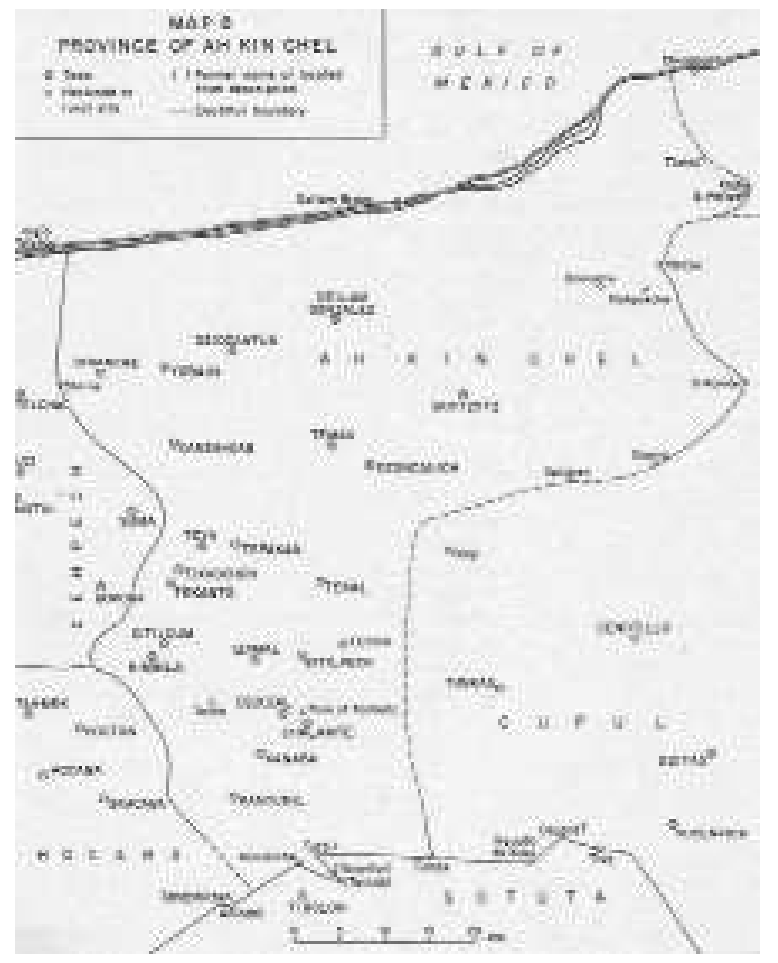

Figura No. 5

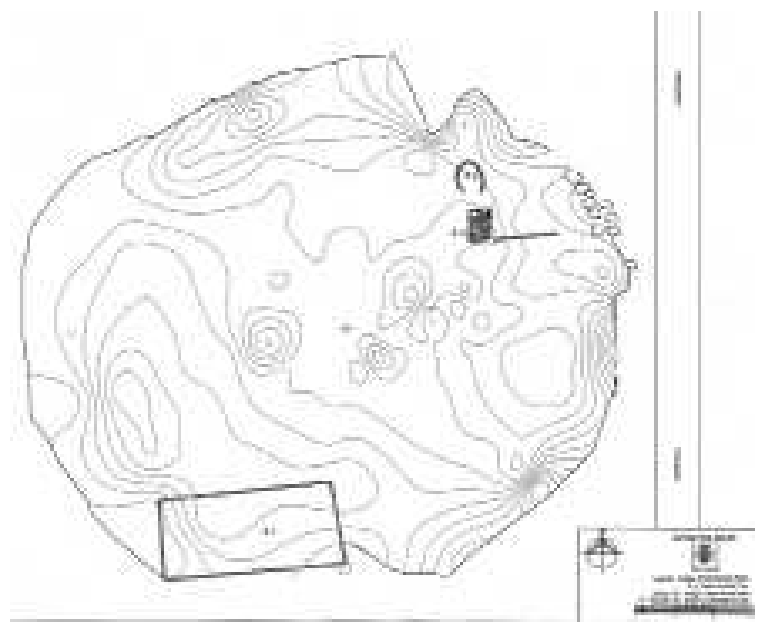

Figura No. 7
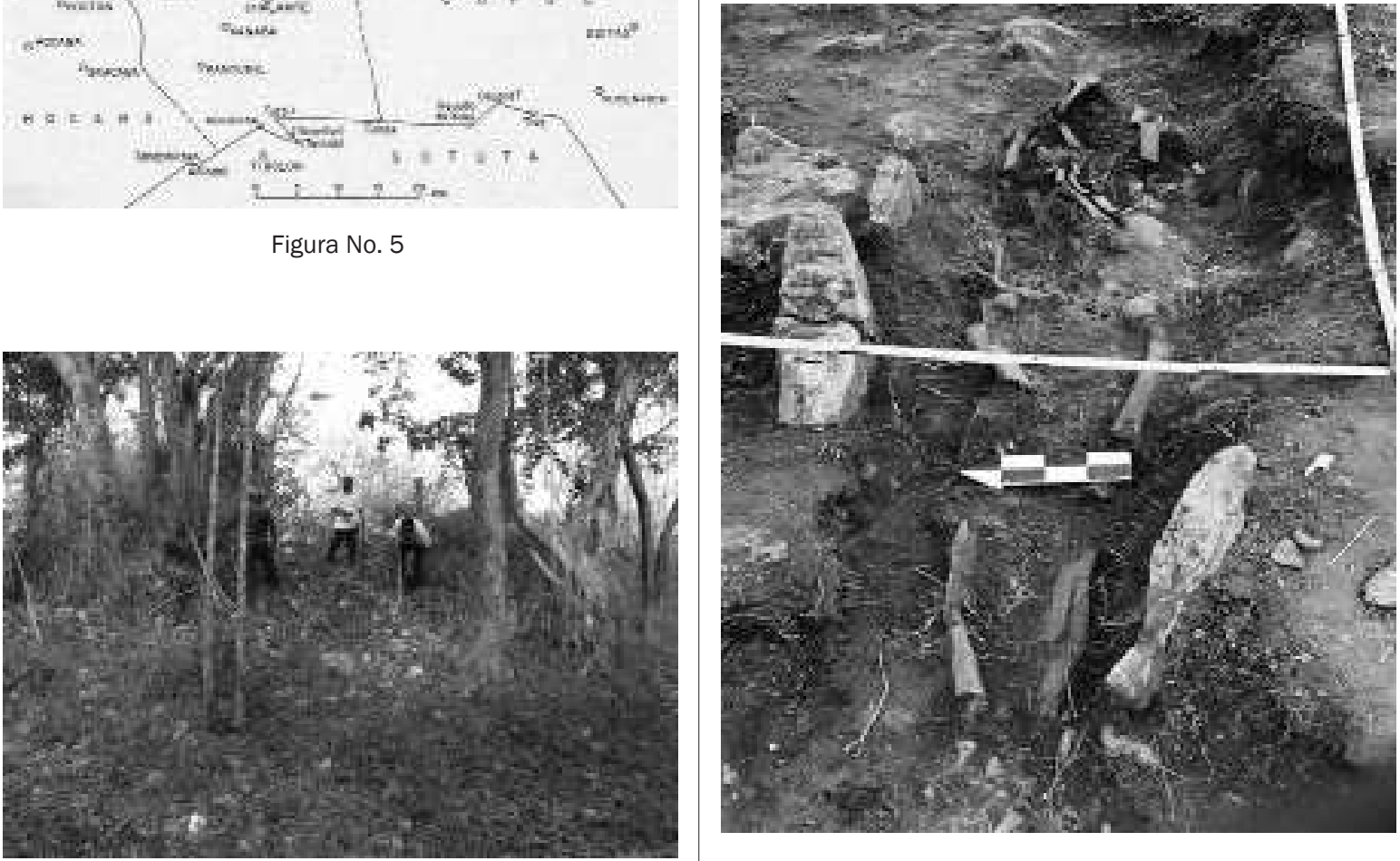

Figura No. 6

Figura No. 8 


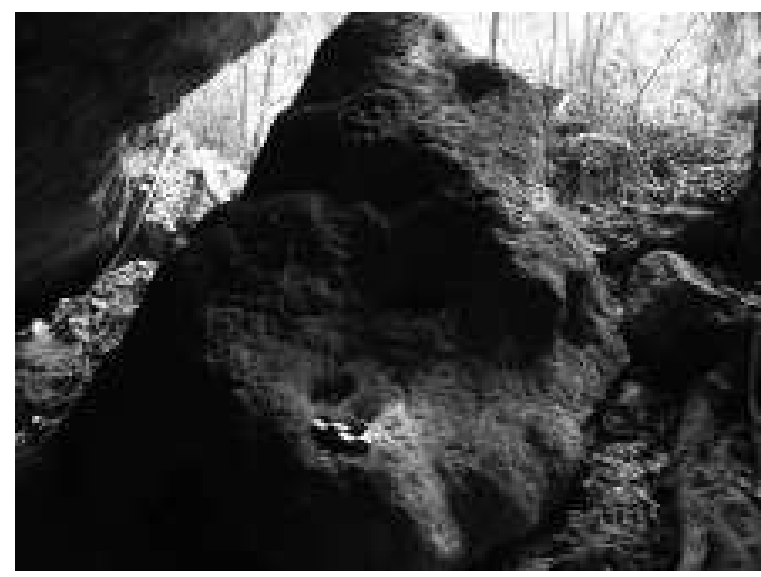

Figura No. 9

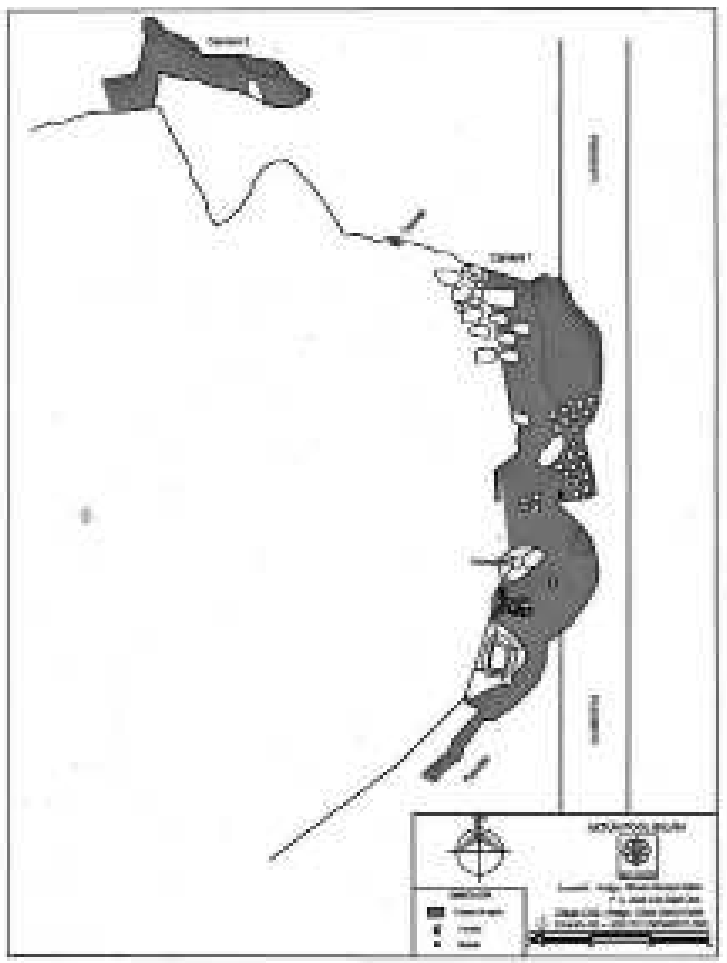

Figura No. 10

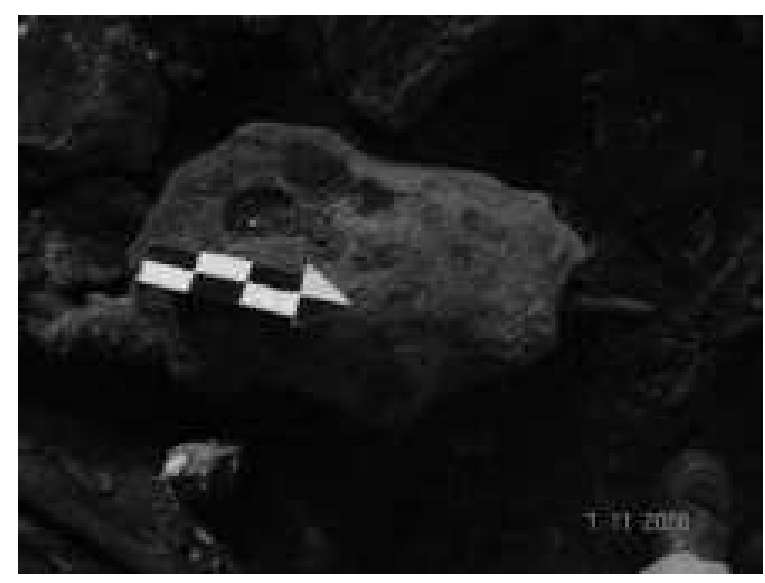

Figura No. 11

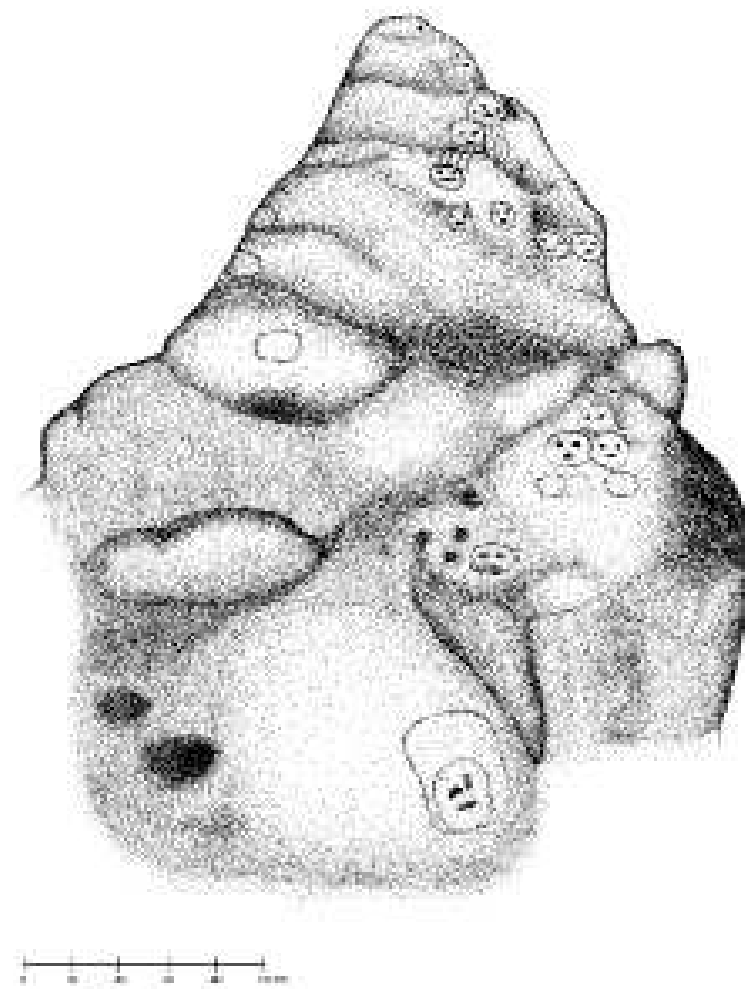

Figura No. 12 


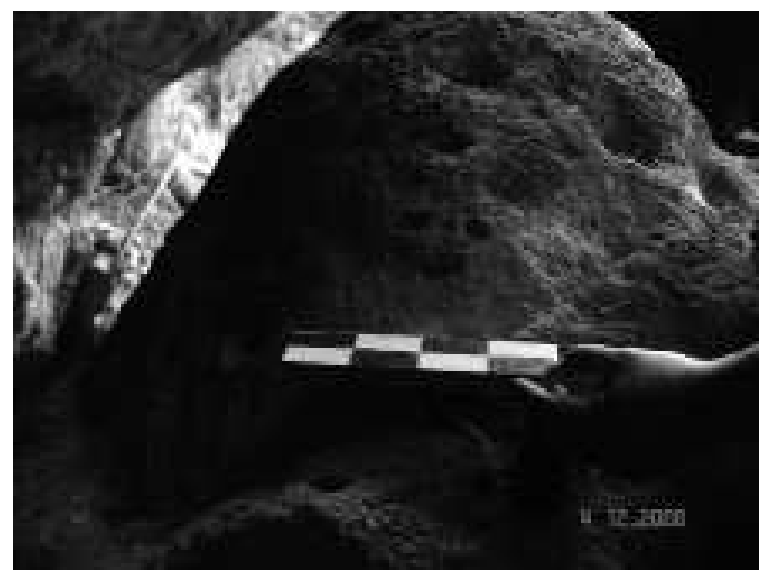

Figura No. 13

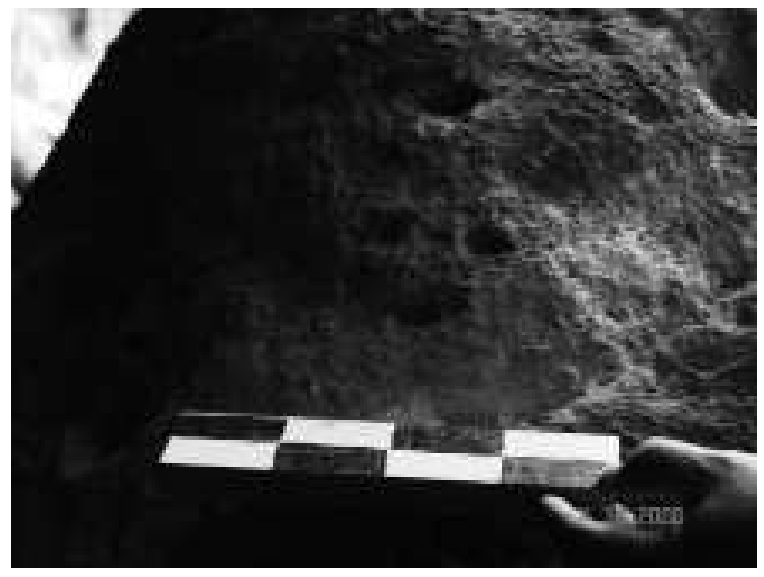

Figura No. 14

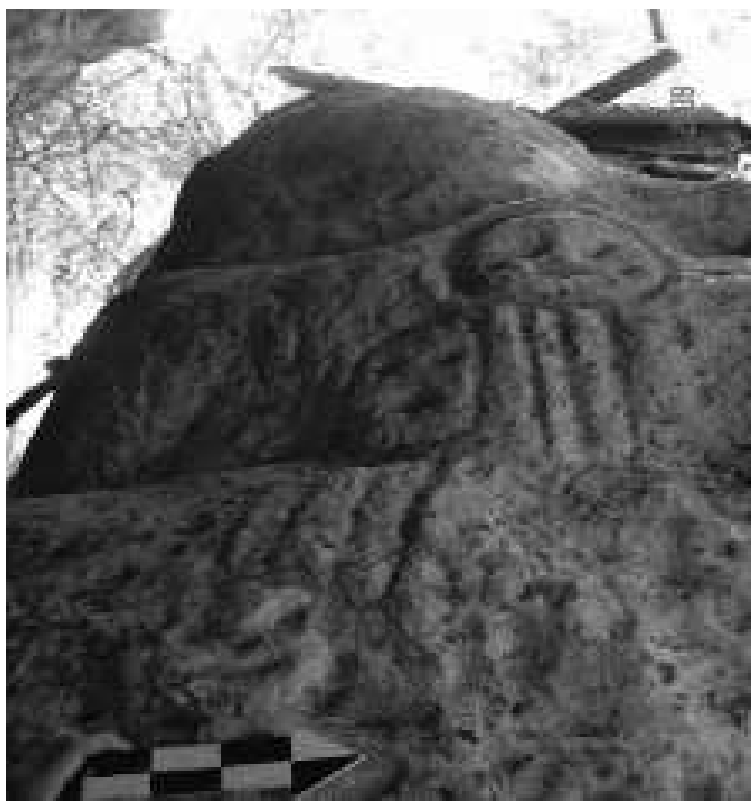

Figura No. 15

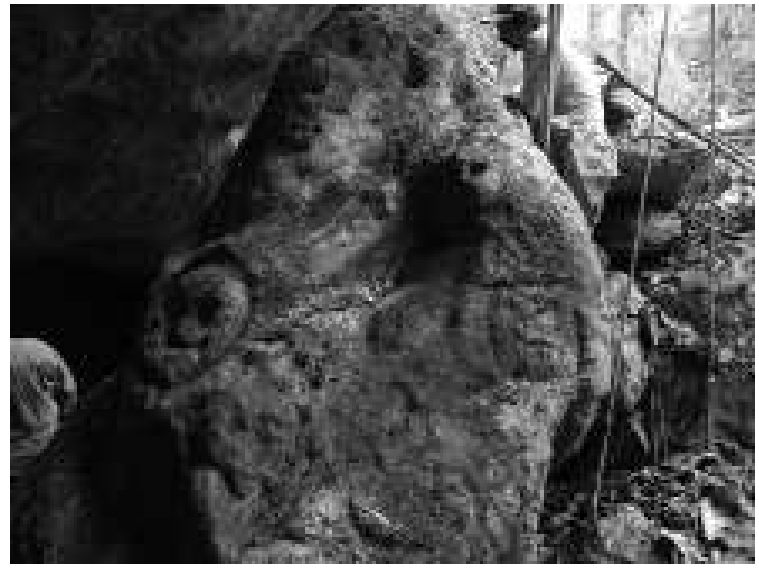

Figura No. 16 


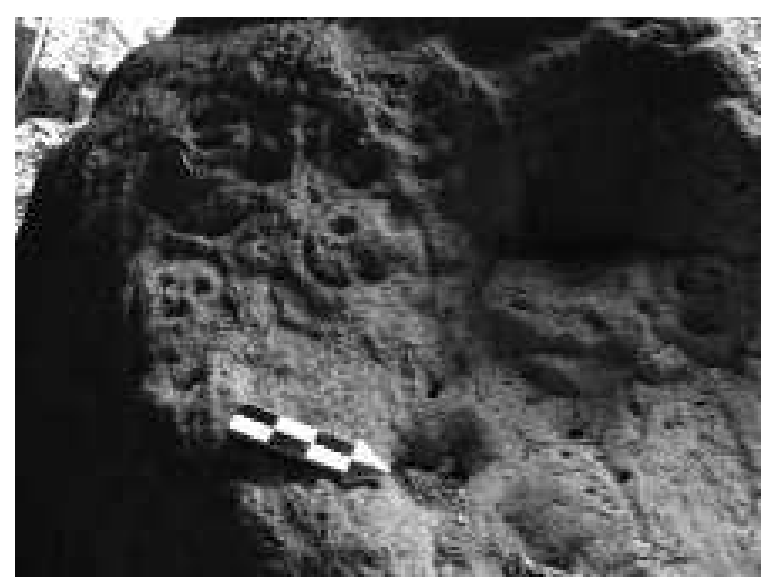

Figura No. 17

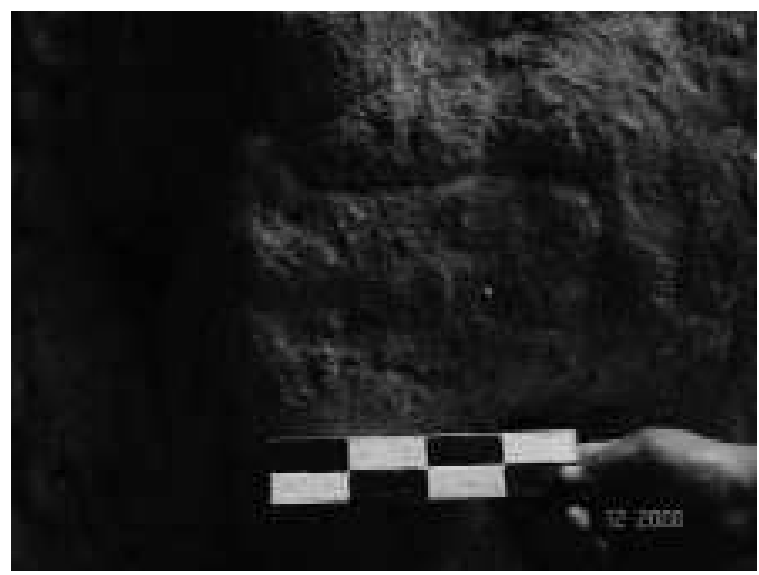

Figura No. 18

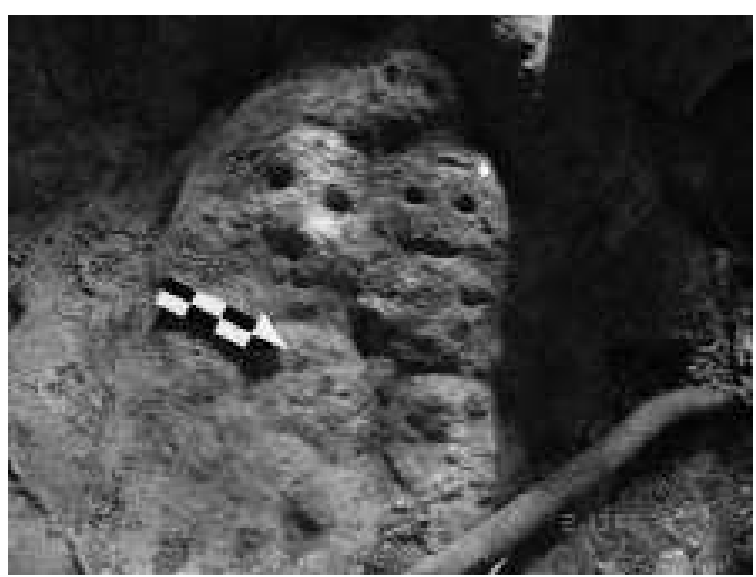

Figura No. 19

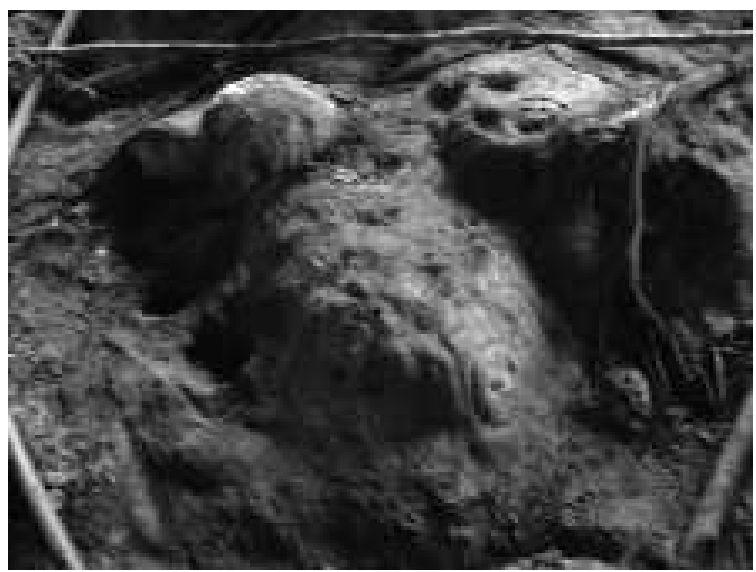

Figura No. 20

Revista LiminaR. Estudios sociales y humanísticos, año 7, vol. VII, núm. 1, junio de 2009, Tuxtla Gutiérrez, Chiapas, México. ISSN: 1665-8027 


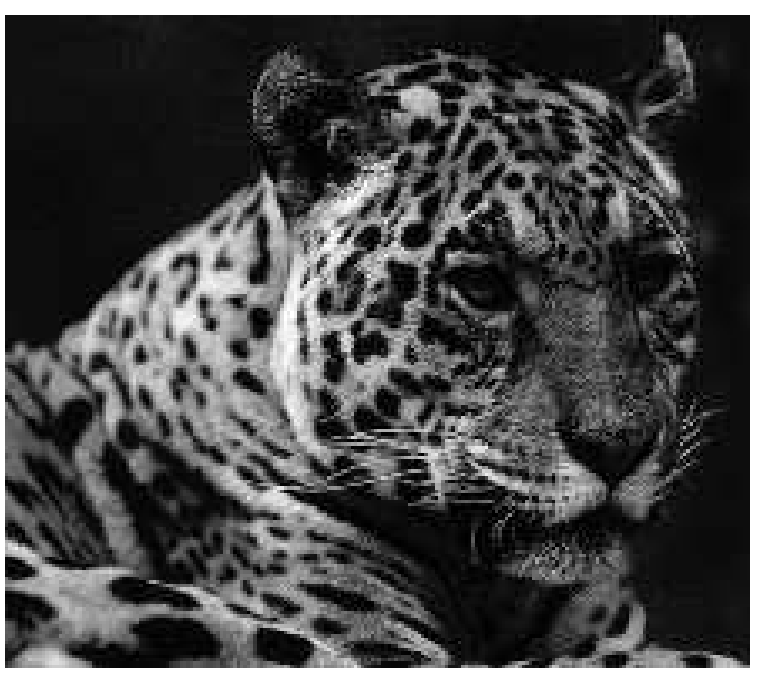

Figura No. 21
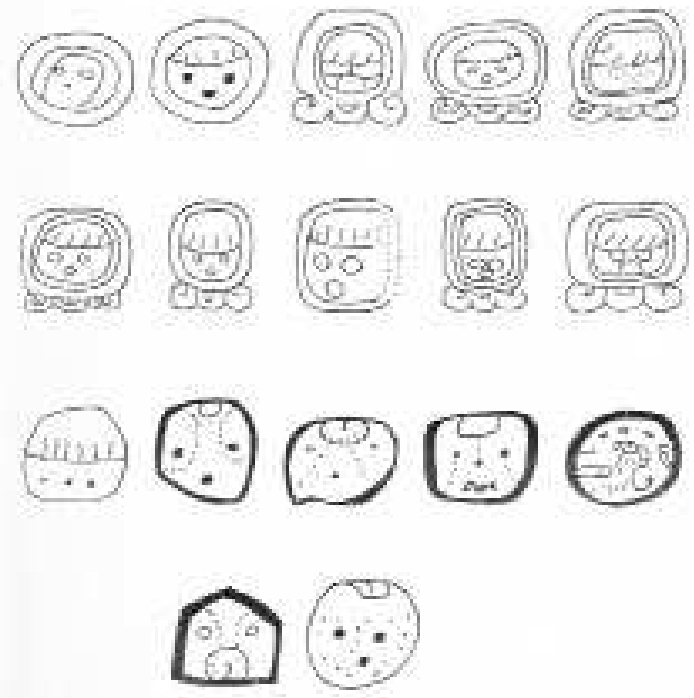

Figura No. 22
(60) (6) (60)

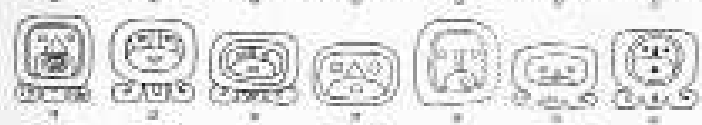
(Q)

Figura No. 23 